\title{
$F$-Region Irregularities Studied by Scintillation of Signals From Satellites
}

\author{
K. C. Yeh and G. W. Swenson, Jr. \\ Contribution From the Department of Electrical Engineering, University of Illinois, Urbana, Ill.
}

(Received April 9, 1964)

\begin{abstract}
Scintillation of radio signals from earth satellites has been studied for five years during the declining phase of the sunspot cycle. It is found that the character of the scintillation, and thus, probably, of the ionospheric irregularities that cause them, vary systematically with geomagnetic latitude, season of the year, time of day, and phase of the sunspot cycle. Nighttime scintillation occurs in the $F$-region, main ly at heights of about $350 \mathrm{~km}$. This type of scintillation in most cases results from first-order scattering from weak, field-alined irregularities in electron density. In the Northern Hemisphere such scintillations are observed north of a certain parallel of geomagnetic latitude, the southern limit varying weakly with magnetic activity. Similar effects are also observed in the Southern Hemisphere. Daytime scintillations also show strong seasonal and sunspot-cycle dependence but very little latitude dependence.

The scintillation observations of the present investigation have been compared with observations of other manifestations of ionospheric irregularities, particularly spread- $F$ and radio "star" scintillation. It has been observed that strong scintillation occurs simultaneously with the occurrence of red auroral arcs. Scintillation, being more common than red arcs, may be a more sensitive indicator of ionospheric disturbances.
\end{abstract}

\section{Introduction}

Ever since the vertical sounding observations of Booker and Wells in 1938 the irregular structure of the ionosphere has been a subject of continued interest. In 1946 renewed interest was generated when the intensity of the radiation from radio stars was observed to fluctuate [Hey et al., 1946]. Later, backscatter sounding [Peterson, 1955], whistler-mode propagation [Helliwell et al., 1956], satellite radio signals [Slee, 1958], and rocket sounding [Calvert et al., 1963] all indicated the existence of irregularities. Despite the number of papers that have been written on the subject, knowledge of the subject is mostly phenomenological and the causative mechanisms remain unknown. Only recently has a theory successfully explained certain equatorial sporadic- $E$ irregularities connected with the electrojet current [Farley, 1963; Maeda et al., 1963] and perhaps also E-region irregularities in the auroral zone. The theory seems to be confirmed experimentally [Bowles et al., 1963]. However, irregularities in the $F$-region in temperate latitudes are also observed regularly and a theory to explain them has yet to be developed.

In this paper are summarized observations of satellite radio signal scintillation during the descending half of the solar cycle.

\subsection{Satellites and Transmitting Frequencies}

The satellites utilized in this study are listed in table 1 .

TABLE 1. Some pertinent information on satellites used in this study

\begin{tabular}{l|l|l|c|c|c}
\hline \multicolumn{1}{c|}{ Name } & Launching date & Radio cutoff date & $\begin{array}{c}\text { Frequencies } \\
\text { transmitted }\end{array}$ & Apogee & Perigee \\
\hline $1958 \delta \delta_{2}$ (Sputnik 3) & Inclination \\
degrees
\end{tabular}




\subsection{Location of Observer}

Data have been obtained from the locations listed in table 2.

The receiving and recording techniques utilized in this study have been discussed elsewhere [Swenson, 1962].

Table 2. Geographic coordinates of observing stations

\begin{tabular}{|c|c|c|c|}
\hline Station & Latitude & Longitude & Data communicated by \\
\hline Urbana & $40.018^{\circ} \mathrm{N}$ & $88.327^{\circ} \mathrm{W}$ & University of Illinois. \\
\hline Baker Lake & $64.3^{\circ} \mathrm{N}$ & $96.1^{\circ} \mathrm{W}$ & Univeristy of mllinois. \\
\hline Aberystwyth & $52.4^{\circ} \mathrm{N}$ & $4.1^{\circ} \mathrm{W}$ & $\begin{array}{l}\text { University College of Wales (W. J. } \\
\text { G. Beynon). }\end{array}$ \\
\hline Blaxland & $33.75^{\circ} \mathrm{S}$ & $209.4^{\circ} \mathrm{W}$ & $\begin{array}{l}\text { Radio Research Board Laboratory } \\
\text { (G. H. Munro). }\end{array}$ \\
\hline Lower Hutt & $41.2^{\circ} \mathrm{S}$ & $185.1^{\circ} \mathrm{W}$ & $\begin{array}{l}\text { Dominion Physical Laboratory (J. } \\
\text { Mawdsley). }\end{array}$ \\
\hline Stanford & $37.4^{\circ} \mathrm{N}$ & $122.6^{\circ} \mathrm{W}$ & Stanford University (O. K. Garriott). \\
\hline
\end{tabular}

\subsection{Sample Records}

Figure 1 displays some typical samples of amplitude scintillation records. It is obvious that the scintillation rate at Urbana is much lower than at Baker Lake.

As the sunspot number and the average scintillation activity declined, lens-like diffraction was observed at times. Figure 2 shows one such record. This is probably the same phenomenon observed by Wild and Roberts [1956]. In this investigation the scintillation phenomenon shown in figure 1 is studied, rather than the phenomenon shown in figure 2 .


(a) URBANA, 2343 CST, JAN 23, 1960. (LEFT TRACE SHOWED SCINTILLATION, RIGHT TRACE NO SCINTILLATION, NOTE THE SPIN AND FARADAY FADINGS. I

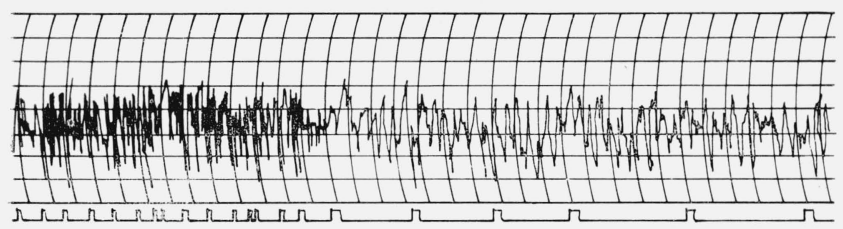

(b) BAKER LAKE, 1015 CST. JAN. 10, 1960. (SECOND MARKS ON THE LOWER SCALE.)

Figure 1. Sample scintillation records on $20 \mathrm{Mc} / \mathrm{s}$ (1959 iota 1).

\section{Statistics of Data}

In the study of seasonal behavior the following definitions are adopted:

Spring, Feb. 15-May 15

Summer, May 15-Aug. 15

Fall, Aug. 15-Nov. 15

Winter, Nov. 15-Feb. 15 (next year).

In table 3 the numbers of Urbana records used in the study are listed. Only passages corresponding to satellite height $300 \mathrm{~km}$ or above are used. This accounts for the small number of passages in the fall season of 1959 when satellite $1958 \delta$ was in a low orbit and 1959 ı not yet launched.

TABLE 3. Number of passes recorded at Urbana $20 \mathrm{Mc} / \mathrm{s}\left(1958 \delta_{2}\right.$ and 1959 ८)

\begin{tabular}{|c|c|c|c|c|c|c|c|}
\hline Fall 58 & Winter 58 & Spring 59 & \multicolumn{2}{|c|}{ Summer 59} & Fall 59 & Winter 59 & Spring 60 \\
\hline \multirow[t]{3}{*}{42} & 61 & 41 & & 67 & 7 & 53 & 48 \\
\hline & & \multicolumn{2}{|c|}{ Summer 60} & \multicolumn{2}{|c|}{ Fall 60} & & \\
\hline & & \multicolumn{2}{|l|}{32} & \multicolumn{2}{|l|}{21} & & \\
\hline
\end{tabular}

$54 \mathrm{Mc} / \mathrm{s}(1960$ o $)$

\begin{tabular}{c|c|c|c}
\hline Spring 62 & Summer 62 & Fall 62 & Winter 62 \\
\cline { 1 - 2 } 82 & 66 & 81 & 76 \\
\hline
\end{tabular}

Since the signal from $1958 \delta_{2}$ was keyed and that from 1959 ८ showed pronounced spin fading a completely quantitative definition of scintillation index is not possible. In order to show the semiquantitative behavior scintillation indices 0,1 , and 2 are assigned to portions of amplitude records by visual inspection. The procedure was used in a previous paper [Yeh and Swenson, 1959] and has been adopted by other observers [Liszka, 1963a]. In investigating the average behavior of scintillation, it is also convenient to present the scintillation index on a percentage basis. Here a linear scale is used so that the average scintillation index of 2 corresponds to 100 percent, 1 to 50 percent, etc. Since $1960 \mathrm{O}_{1}$ is transmitting on $54 \mathrm{Mc} / \mathrm{s}$ with no undesirable modulation, a more quantitative definition of scintillation index is possible. If $A_{0}$ is the average value of the amplitude (or the amplitude in the absence of irregularities) and $\Delta A$ the fluctuations the scintillation index is defined as

$$
S=\left\langle\left(\frac{\Delta A}{A_{0}}\right)^{2}\right\rangle^{\frac{1}{2}}
$$

$S^{2}$ is essentially the ratio of the "noise" power to the average power. 


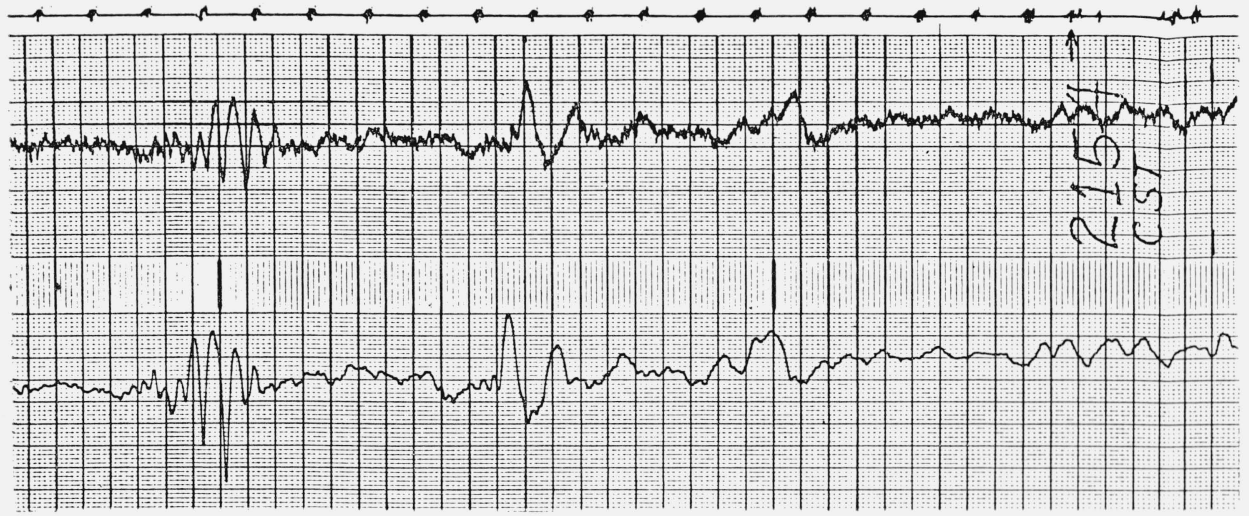

FIGURE 2. Sample records showing diffraction from lens-like irregularities (54 Mc/s, 1961 omicron, April 4, 1962).

The upper trace was for a receiver spaced $2.9 \mathrm{~km}$ from the receiver of the lower trace. Time goes from right to left with second marks indicated at the top.

According to these definitions of scintillation index, table 4 gives the percent occurrences of each kind of scintillation record of interest. This table shows that the scintillation near sunspot minimum (1961 0 data) is not appreciably less common than that near sunspot maximum (1958 $\delta$ and $1959 \iota$ ) even though it is shown in part 6 that the activity is much weaker as the sunspot number decreases. Note that transitions occurred 21 percent of the time near sunspot maximum and only 7 percent of the time near sunspot minimum.

TABLE 4. Scintillation statistics

$1958 \delta_{2}$ and $1959 \iota(20 \mathrm{Mc} / \mathrm{s})$

No scintillation in the entire pass $S=2$ for the entire pass

$S=2$ for the entire pass

At least part of the pass has $S=0$

At least part of the pass has scintillation

Transition observed from $S=0$ to 2 or vice versa

$19610(54 \mathrm{Mc} / \mathrm{s})$

No scintillation in the entire pass

$0<S \leq 0.2$ for the entire pass

$0.2<S$ for the entire pass

At least part of the pass has $S=0$

At least part of the pass has $0<S<0.2$

At least part of the pass has $S>0$.

Transition observed from $S=0$ to $S>0.2$ or vice versa

In the presence of irregularities the wave is scattered; hence, the signal received on the ground is the resultant of a large number of vectors. When the scattering is sufficiently intense so that the amplitude of these vectors is random and the phase is uniformly distributed, the distribution of the amplitude is Rayleigh, otherwise it is some generalization of Rayleigh distribution. If in addition to these random vectors there is a constant vector the amplitude becomes Rice-distributed [Rice, 1944 and 1945]. The Rice distribution approaches the Gaussian distribution as the constant vector becomes relatively large.
Most of the scintillation records show Gaussian distribution, but at Baker Lake in 1959 and 1960 the amplitude may also have Rice and even Rayleigh distributions, indicating the existence of multiple scattering. Figure 3 shows a few amplitude distributions.

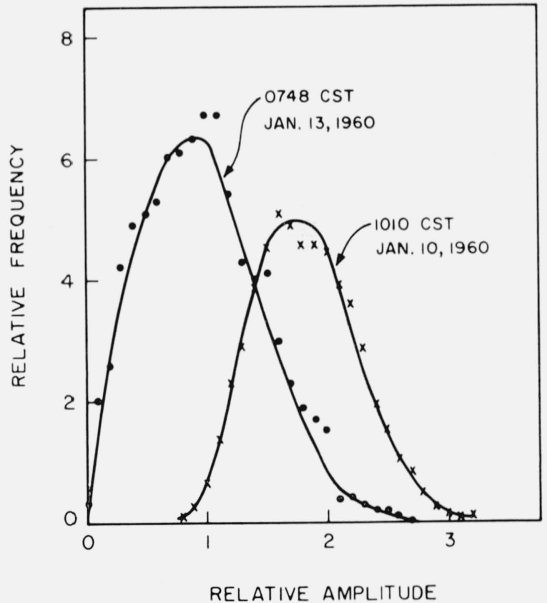

Figure 3. Earamples of amplitude distributions (20 $\mathrm{Mc} / \mathrm{s}$ Baker Lake).

Figure 1 showed that the scintillation rate at Baker Lake is much faster than that at Urbana. A similar effect is also shown in figure 4 where typical correlation functions of these two stations are plotted. The autocorrelation functions are very similar to those obtained theoretically [Yeh, 1962]. 


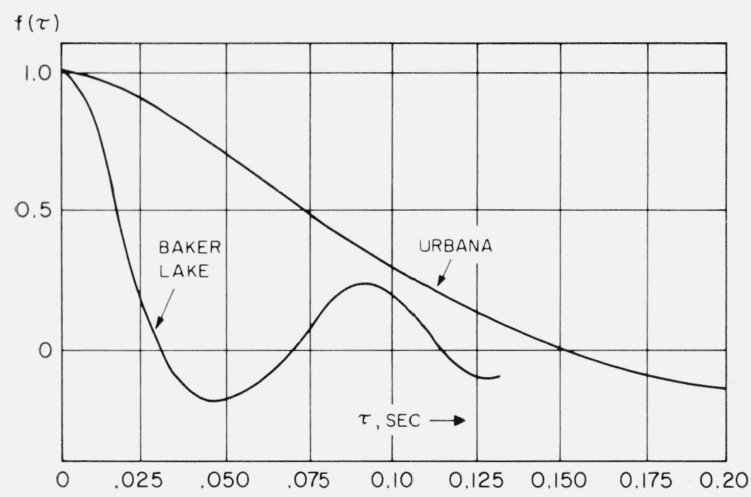

Figure 4. Autoccrrelograms of scintillating amplitude of satellite signals on $20 \mathrm{Mc} / \mathrm{s}$.

\section{Dependence of Scintillation on Geometry}

The study of scintillation is complicated by its dependence on geometry. Before proceeding to study the properties of scintillation-producing irregularities it is important to understand the geometrical aspects of the problem. In his important review paper, Booker [1958] examined the zenith angle dependence of the amplitude scintillation and found disagreement between his simple theory and the experimental results obtained at Manchester and thus termed anomalous the Manchester zenith angle data. Further observations [Little et al., 1962] confirmed earlier Manchester results concerning the relative absence of zenith angle effect - much below Booker's theoretically predicted values. In the meantime further theoretical calculations [Yeh, 1962; Briggs and Parkin, 1963] also demonstrated that the weak dependence of scintillation on zenith angle for a high latitude station is attributable to the compensating effects of magnetic field alinement of anisotropic irregularities and the effective thickness of the region of irregularities.

There is at present enough experimental evidence to indicate beyond question that the scintillationproducing irregularities are in the ionosphere, ranging from $100 \mathrm{~km}$ up to perhaps $1000 \mathrm{~km}$. For discussion on heights, see [Chivers, 1963a]. Indications are that the region may be quite thin at times and may also be thick at other times, depending on the degree of disturbance and the geomagnetic location of the observer. It is also found experimentally that irregularities may be at different heights in different parts of the sky [Yeh et al., 1963]. 'These irregularities are really fluctuations in the electron density, hence the stochastic nature of the problem. The correlation function of the density fluctuations has ellipsoidal symmetry with dimensions of the order $1 \mathrm{~km}$ by 5 to $10 \mathrm{~km}$, with major axis alined with the earth's magnetic field lines [Spencer, 1955; DeBarber et al., 1962]. The anisotropic nature of these irregularities introduces added complications in the theory, but they are very essential in order to interpret correctly the experimental data. Therefore, the physi- cal model usually chosen is either a plane slab or a spherical shell within which are contained anisotropic fluctuations in the dielectric constant (or the electron density). The receiver is situated approximately $300 \mathrm{~km}$ below the slab (or shell), and the transmitter may be anywhere from the bottom of the slab (or shell) to an infinite distance above the slab.

\subsection{Zenith Angle Dependence}

If the electron density fluctuation is assumed to be a stationary process (with respect to spatial coordinates), the amplitude and the phase of the wave after passing through the region of irregularities are not necessarily stationary in the statistical sense (with respect to time) as the satellite speeds across the sky. The nonstationarity comes about because of three factors: the change in the effective thickness of the slab, the change in the direction of propagation with respect to the elongation of the correlation function of the electron density, and the change in the effective distances between the transmitting satellite and the slab, and between the slab and the receiver. The effect of the last factor is relatively small in a single satellite passage and shall be ignored temporarily and taken up again in a later section.

A theoretical discussion of the zenith angle dependence is given by Briggs and Parkin [1963] using the "phase changing screen" concept and the diffraction theory. Using the scattering approach, a study of two special cases has been carried out [Yeh, 1962] and it is shown that for a station with magnetic dip angle $70^{\circ}$ the zenith angle dependence is expected to be weak.

Experimental study of the zenith angle dependence is difficult because of the scintillation dependence on other factors (e.g., geomagnetic latitude, etc.). Most of the radio star scintillation data [Booker, 1958; Little et al., 1962] tend to support weak zenith angle dependence, especially if the angle is less than about $60^{\circ}$.

\subsection{Size of Irregularities}

In formulating the problem it is usually assumed that the correlation function of the dielectric constant or of the electron density is Gaussian with prolate spheroidal symmetry. The assumption of Gaussian shape is purely for convenience and has no physical basis. But even with this assumption the correlations of the amplitude and the phase are not necessarily Gaussian in general. It should also be cautioned that the correlation distances of the wave amplitude and phase are not simply obtained by introducing the geometric magnification factor even in the limit of weak scattering. The anisotropic nature of these irregularities may produce 50 percent error, which is appreciable in the more refined measurements.

The average number of maxima of the amplitude in one second is uniquely related to the correlation distance for a given form of power spectrum [Rice, 
1944 and 1945]. Therefore, if the received signals (essentially narrow band noise) are assumed to have identical power spectra, the counting of maxima could give directly the size of irregularities. The assumption here is constancy in the shape of the power spectrum, and it is very doubtful whether this is valid for scintillating signals. Nevertheless, from the standpoint of data analysis, the counting of maxima is a much simpler task than computation of correlation functions. For purposes of rough estimates the counting procedure will be used, keeping in mind that the values so obtained may be off by as much as 50 percent.

The results of such a rough analysis are shown in table 5. Only portions of the records corresponding to satellite positions near points of closest approach to the receiving station have been used. Hence, the measured size is roughly the dimension perpendicular to the magnetic field lines since all listed stations have high magnetic dip angles. In table 5 we see that the sizes measured at Houghton and Adak are nearly equal. Although Adak is at a higher 'latitude than Houghton, they are both close to the same auroral isochasm, as derived theoretically by Vestine and Sibley [1960]. This observation suggests a connection between the scintillation and the geomagnetic field. It is also interesting to note that the sizes are larger at Houghton than at either higher (Baker Lake) or lower (Urbana) magnetic latitudes. It is not vet known whether this is a genuine effect that holds at all times or whether it was true only during the three months that observations were made.

Before leaving this section it should be mentioned that the size obtained depends on a theory which assumes "weak" scattering. This assumption appears to be valid in most cases on $20 \mathrm{Mc} / \mathrm{s}$ (see 3.5). However, in January 1960 the scintillation at Baker Lake was extremely violent and the amplitude may even have a Rayleigh probability density (see fig. 3), suggesting that multiple scattering must be taken into account. Therefore, the value of $0.26 \mathrm{~km}$ given for Baker Lake station in table 5 must be taken as a lower limit.

TABLE 5. Scintillation rate (peaks/s) and size $(\mathrm{km})$ of irregularities perpendicular to the earth's magnetic field lines

\begin{tabular}{|c|c|c|c|c|}
\hline & Baker Lake & Houghton & Adak & Urbana \\
\hline $\begin{array}{l}\text { January } 1960 \\
\left(1958 \Delta_{2}, 20 \mathrm{Mc} / \mathrm{s}\right)_{\ldots}\end{array}$ & $\begin{aligned} & 30 \pm 6 \\
0.26 & \pm 0.071\end{aligned}$ & $\overline{-}$ & $\overline{-}$ & $\overline{-}$ \\
\hline $\begin{array}{c}\text { December 1961-February } \\
1962 \\
\text { (Nora-Alice II, 20 } \begin{array}{c}\text { Me/s) } \\
\text { Size_-_ }\end{array}\end{array}$ & $\begin{array}{l}8.0 \pm 4.9 \\
1.8 \pm 1.4\end{array}$ & $\begin{array}{l}1.5 \pm 0.7 \\
5.4 \pm 2.0\end{array}$ & $\begin{array}{l}1.3 \pm 0.5 \\
5.8 \pm 2.0\end{array}$ & $\begin{array}{l}2.6 \pm 0.7 \\
3.0 \pm 0.7\end{array}$ \\
\hline
\end{tabular}

1 This value may be in error due to possible presence of multiple scattering.

\subsection{Height of Irregularities}

The earliest study of irregularity heights was made by means of the vertical incidence sounder [Booker and Wells, 1938]. Only when the irregu- larities appear below the peak of the $F 2$ region can such measurements be made. In the case of radio star observations, heights can be estimated approximately if there are simultaneous measurements of amplitude and phase scintillations [Hewish, 1952]. Some of these early results have been summarized by Chivers [1963a]. Since the advent of rockets and satellites, measurement techniques have been much improved. In a few cases, irregularities at heights from $400 \mathrm{~km}$ to $1000 \mathrm{~km}$ have been observed by means of rockets [Calvert et al., 1963]. Among the various satellite techniques, two give the most unambiguous results; both are spaced-receiver methods.

The first method makes use of the so-called "edge" effect. As mentioned in 2.1, radio signals received from the satellite often display a sharp transition from slow, quasi-periodic, Faraday fading to fast, random fluctuations in amplitude, indicating that the ray has just intercepted and passed the edge of a patch containing irregularities. If two receivers are placed parallel to the subsatellite track at a distance somewhat more than $10 \mathrm{~km}$ apart, a difference of a few seconds is observed in the time of transition as seen from the two stations. By triangulation, the height of the irregularities can be computed. This method has been used by a number of investigators [Parthasarathy et al., 1959; Munro, 1963]. A sample record taken at the University of Illinois is shown in figure 5. The height deduced for this record is $395 \pm 10 \mathrm{~km}$.

The second method depends on the correlation of the signals received by two closely spaced receivers. The spacing here is usually not more than a few kilometers. By noting the similar fades on two or more receivers, the height can be computed by triangulation. This method has also been used by a number of investigators [Frihagen and Trøim, 1960; Basler and DeWitt, 1962; DeBarber et al., 1963; Liszka, 1963b; Jespersen and Kamas, 1963]. The results of all these investigations indicate that these

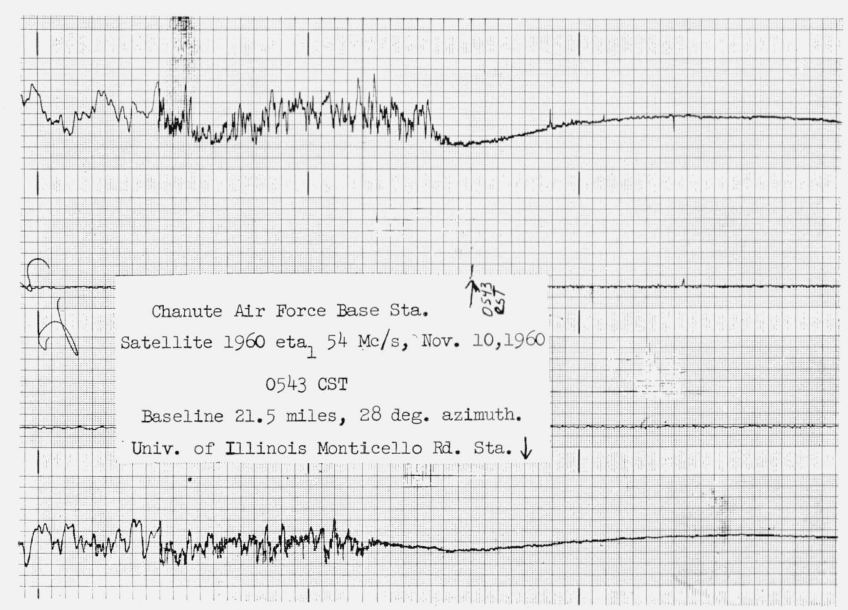

Figure 5. Sample records showing time delay in the onset of scintillation (edge effect) (time delay $=5.25 \pm 0.25 \mathrm{~s}$ ). 
irregularities may appear at heights ranging from $100 \mathrm{~km}$ to $1000 \mathrm{~km}$ above the surface of the earth. Because of insufficient data these past results do not give statistical information about the height distribution of irregularities. The results of a more detailed study, using data from the Urbana station, are summarized in figure 6 . The work of J. P. McClure, who is preparing a more extensive and detailed study of heights, is here acknowledged. The data consist of approximately $150 \mathrm{~min}$ of scintillation records taken in 1962, mostly in November and December. Note that most of the irregularities are concentrated in the $F$-region in a narrow height range from $300 \mathrm{~km}$ to $400 \mathrm{~km}$ with a very minor secondary E-region peak. These data are very important in the search for an explanation of the existence of irregularities.

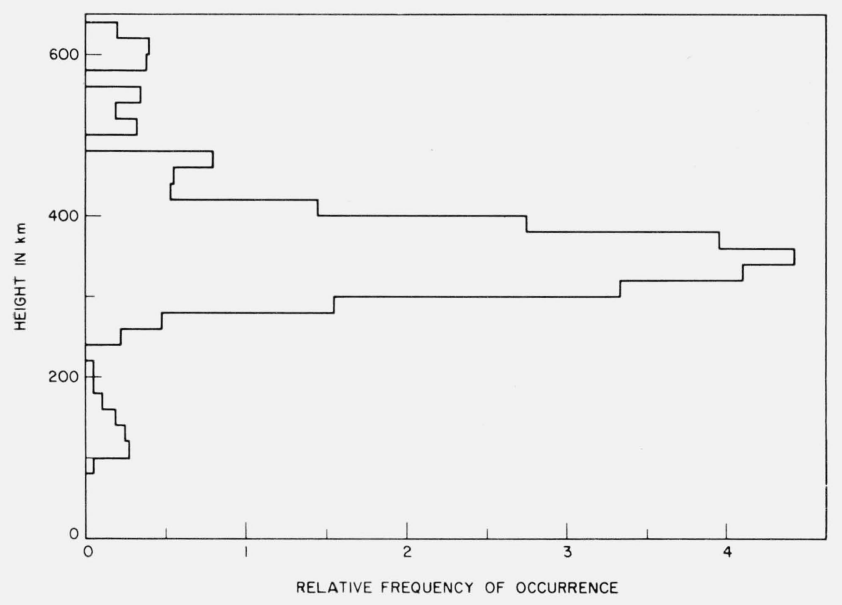

Figure 6. Height distribution of irregularities.

\subsection{Height of Satellite}

The problem of scintillation dependence on the height of the satellite has been studied theoretically [Yeh, 1962]. It is shown that the amplitude scintillation increases monotonically, while the phase scintillation decreases monotonically, as the height of the satellite above the irregularities increases.

The corresponding experimental study is usually very difficult since the height of the satellite changes very slowly, and during this time changes due to other effects (e.g., diurnal, seasonal, or the change in irregularity height etc.) may overshadow the relatively weak dependence on satellite height. On one occasion during the last few weeks of the life of Sputnik $3\left(\begin{array}{lll}1958 & \delta_{2}\end{array}\right)$ it was possible to make a rough study of this nature. During these few weeks the orbital period was decreasing rapidly and the satellite was transmitting a $\mathrm{CW}$ signal on $20 \mathrm{Mc} / \mathrm{s}$, only when in sunlight. The scintillation index was obtained when the satellite was close to its point of closest approach at Baker Lake. The result is depicted in figure 7 , which shows that as the satellite decreases

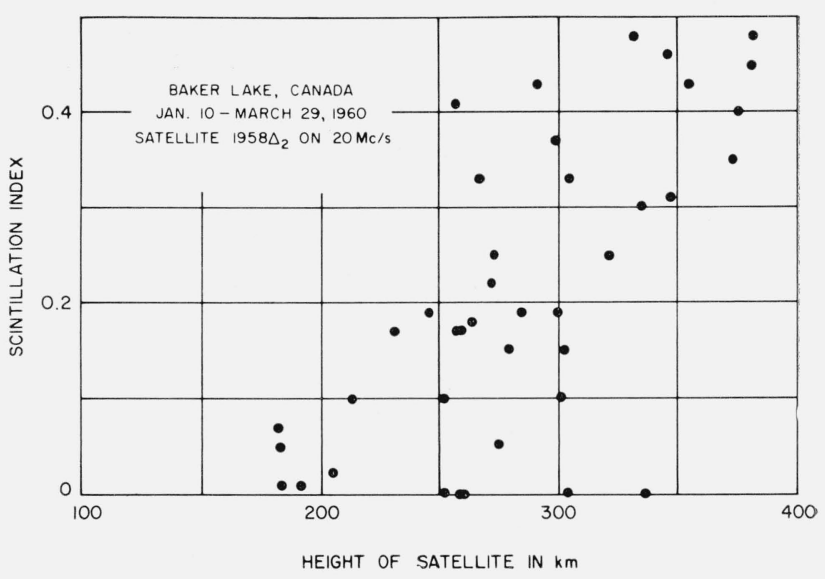

FiguRe 7. Dependence of scintillation on the height of the satellite.

in height the amplitude scintillation also decreases as predicted by the theory. There is also a large spread in these points, suggesting that even during the relatively short period of several weeks other effects are also important. Another feature of figure 7 is that the scintillation was negligible when the satellite was below about $200 \mathrm{~km}$, which gives the lower boundary of the region of irregularities. This observation is in agreement with the height distribution given in figure 6 .

\subsection{Frequency Dependence}

The dependence of scintillation on frequency is quite complicated because the geometry usually places the receiver at such a place that neither farfield nor near-field approximations are valid. A study of frequency dependence has been made with radio-star scintillations [Chivers, 1960a]. In the case of satellite scintillations such a study has been

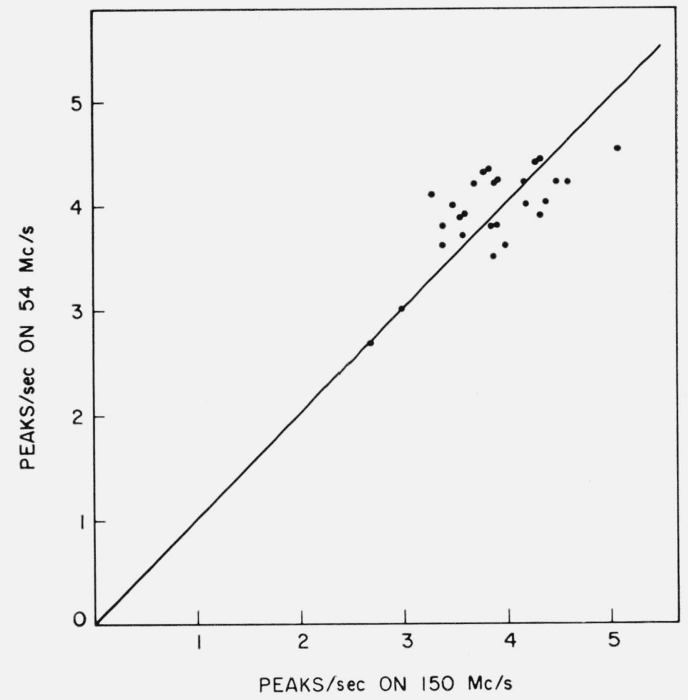

Figure 8. Scintillation rate dependence on frequency Mar.Sept. 1962 (1961 omicron). 
hampered by the lack of a suitable multifrequency satellite and has yet to be undertaken. According to the weak-random-medium theory the average rate of scintillation is almost independent of frequency. This has been found to be true in scintillations of radio stars [Booker, 1958; Chivers, 1960a]. Some data collected at Urbana on $54 \mathrm{Mc} / \mathrm{s}$ and $150 \mathrm{Mc} / \mathrm{s}$ from 1961 omicron are given in figure 8 . The scintillation rate is defined here as the average number of peaks per second. The closeness of these points to the straight line indicates the lack of dependence on frequency. This is an excellent check on the validity of application of the weak-randommedium theory. Hence, at least during the period investigated, the single-scatter theory of the weak random medium seems to be applicable at a frequency of $54 \mathrm{Mc} / \mathrm{s}$ or higher.

\section{Morphology of Irregularities}

The study of irregularities by means of satellite radio signals has been carried out for about one-half of the present sunspot cycle and it is now possible to summarize the results. Related studies have also been carried out by many investigators [Kent, 1959; Liszka, 1963a and 1963b; Munro, 1963; Rawer, 1962; Singleton and Lynch, 1962; Yeh and Swenson, 1959].

\subsection{Diurnal Variation}

Scintillation is predominately a nighttime phenomenon but it is observed occasionally in the daytime as well. For comparison purposes, the diurnal behavior of scintillation on $20 \mathrm{Mc} / \mathrm{s}$ for four seasons near the sunspot maximum (Satellites $1959 \Delta_{2}$ and $\left.1959 \iota_{1}\right)$ and on $54 \mathrm{Mc} / \mathrm{s}$ for similar periods near the sunspot minimum $\left(\begin{array}{ll}1961 & o_{1}\end{array}\right)$ are shown in figures 9 and 10 , respectively. One
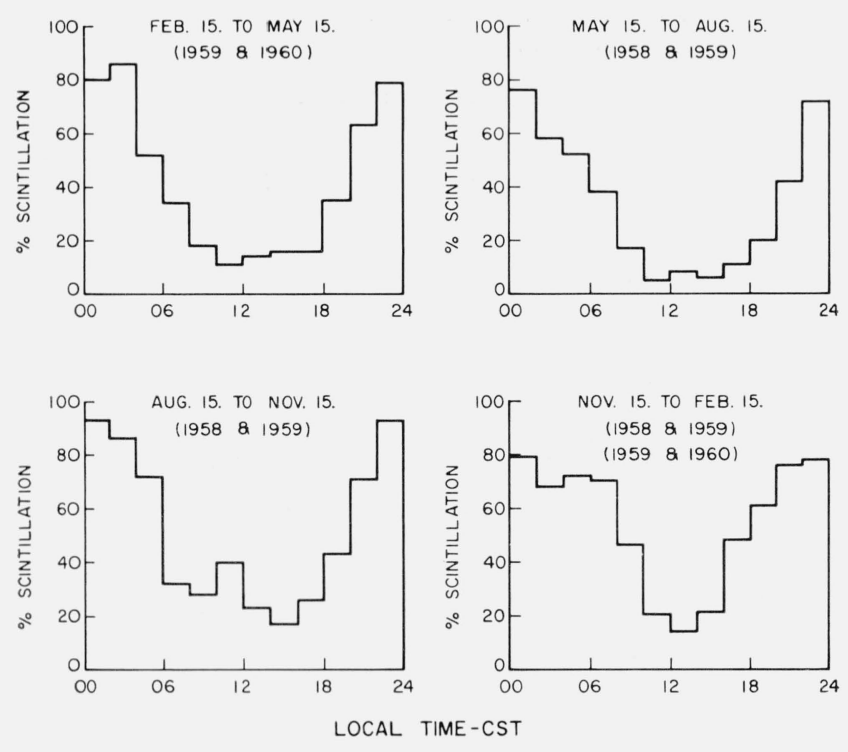

Figure 9. Diurnal variation of scintillation on $20 \mathrm{Mc} / \mathrm{s}$ near sunspot maximum (1958 delta 2 and 1959 iota 1).
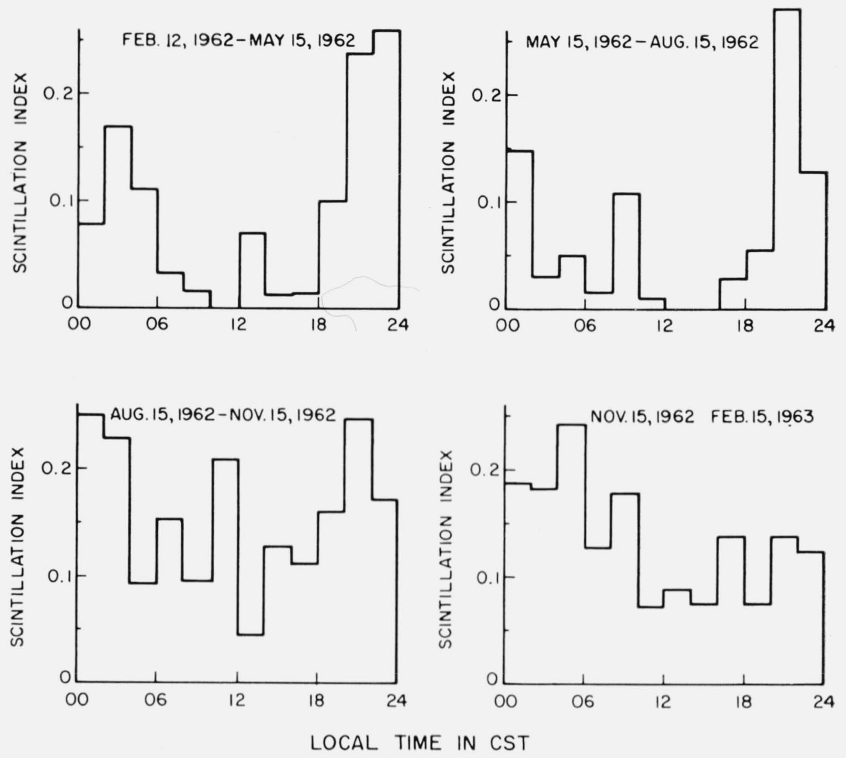

Figure 10. Diurnal variation of scintillation on $54 \mathrm{Mc} / \mathrm{s}$ near sunspot minimum (1961 omicron).

interesting observation is that the diurnal variation seems weakest in the winter near sunspot minimum.

\subsection{Latitude Dependence of Nighttime Scintillation}

The early observations of satellite scintillations at night indicated strong dependence on the geomagnetic latitude. Nearly always, a satellite coming from the north displayed scintillation until it arrived overhead at Urbana; then as it continued southeastward, the scintillation suddenly disappeared and the signal displayed regular Faraday fading. Northbound passages showed transitions in the opposite sense with the scintillation often continuing to the northern radio horizon. This behavior, observed near the sunspot maximum, occurred during more than 20 percent of all the recorded passages (see table 4). Similar transitions have also been reported to occur at Cambridge, England [Kent, 1959]; Vancouver, Canada [DeMendonca, 1960]; and Boston, Mass. [Aarons et al., 1963], which all lie close to the same theoretical auroral isochasm as computed by Vestine and Sibley [1960]. A typical group of such transitions is shown in figure 11 . In computing the location of the transition points it has been assumed that the irregularities occurred at a constant height of $300 \mathrm{~km}$.

Near the end of 1961 a $20 \mathrm{Mc} / \mathrm{s}$ radio transmitter, Nora-Alice 1, was installed on Satellite $1961 \alpha \gamma_{1}$ (Discoverer 32) and launched into a polar orbit. The satellite remained in orbit for one month. During this period data were obtained at five of the stations listed in table 1: Aberystwyth, Blaxland, Lower Hutt, Stanford, and Urbana. All of these stations observed transitions at night, as shown in figure 12. All lie close to the auroral 


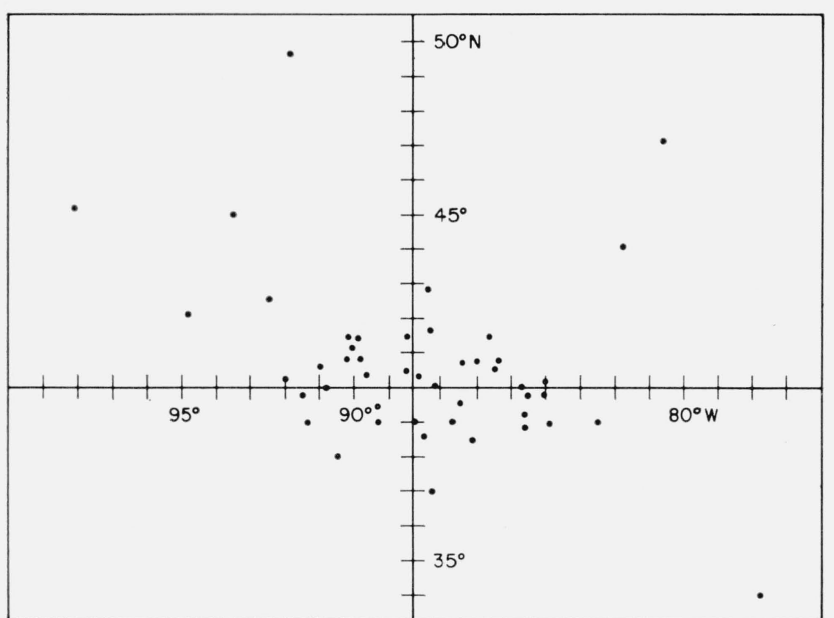

FIgURe 11. A typical group of scintillation transitions observed at University of Illinois on $20 \mathrm{Mc} / \mathrm{s}$ satellites at night.

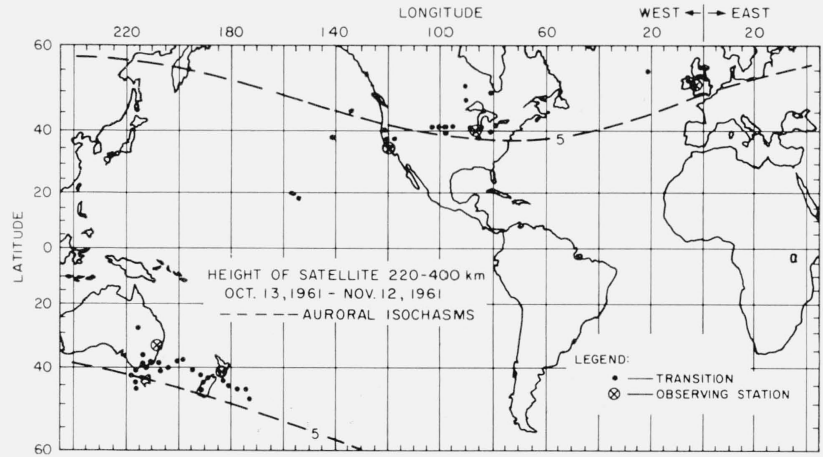

Figure 12. Transitions of $20 \mathrm{Mc} / \mathrm{s}$ signals from satellite Nora-Alice $1 \quad(1961 \alpha \gamma)$ observed near local midnight.

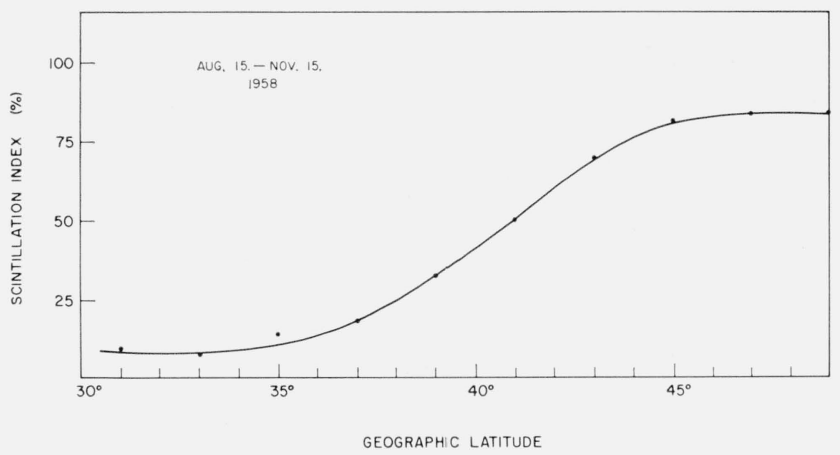

FIgure 13. Latitude dependence of nighttime scintillations on $20 \mathrm{Mc} / \mathrm{s}$ (1958 fall).

isochasms "5" [Vestine and Sibley, 1960] in the Northern and Southern Hemispheres, respectively. As the satellite height varied from 220 to $400 \mathrm{~km}$, little error in the geographic position of the transition point is introduced by the assumption that the irregularities are at the same height as the satellite.
Figure 13 shows one example of the statistical behavior of nighttime scintillations as a function of latitude. In this figure no attempt has been made to remove the geometric dependence discussed in section 3. The variation of scintillation index is interpreted as predominately latitude-dependent for the following reasons: (1) As mentioned earlier, because of the anisotropy in the irregularities, the zenith-angle dependence should be relatively weak, at least in the range considered, (2) the frequent occurrence of transitions indicates strong latitude dependence, and (3) according to the theory [Briggs and Parkin, 1963; Yeh, 1962] and observational evidence [Singleton and Lynch, 1962] scintillations should be more pronounced when propagation is parallel with the earth's magnetic field lines than when it is perpendicular to the field lines. The opposite suggestion of Mawdsley [1960] has been criticized by Frihagen and Trфim [1961], Briggs and Parkin [1963], and Singleton and Lynch [1962]. For an observer in the Northern Hemisphere this means that the scintillation dependence due to zenith angle alone should be more pronounced when the satellite is to the south (lower latitude) than when it is to the north (higher latitude). Such an effect does not show up in figure 13. The conclusion is that near sunspot maximum the latitude dependence is so strong that it overshadows other minor effects.

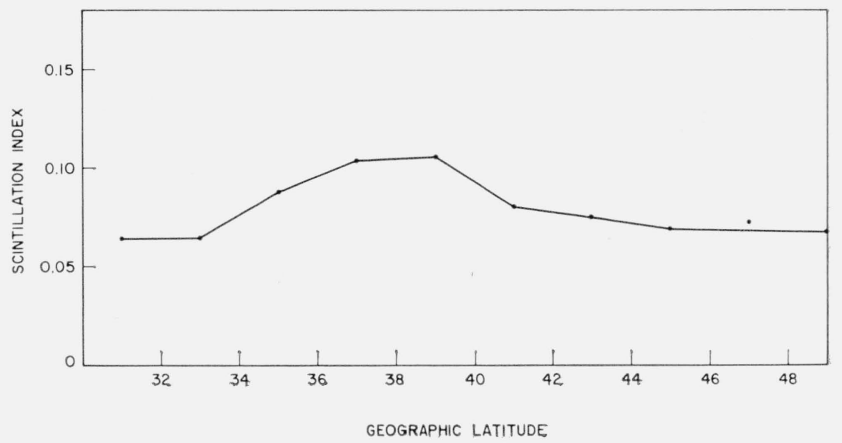

FIGURE 14. Latitude dependence of nighttime scintillation on $54 \mathrm{Mc} / \mathrm{s}$ (1962 winter).

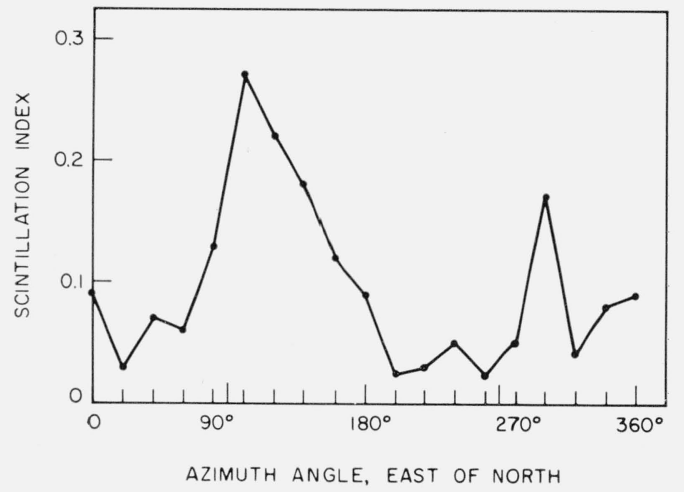

FIgURE 15. Azimuth dependence of scintillation on $54 \mathrm{Mc} / \mathrm{s}$ (1962 winter, nighttime passages with zenith angle 40 to $\left.50^{\circ}\right)$. 
An example of scintillation dependence on latitude during sunspot minimum is shown in figure 14 . Here the behavior is distinctly different; i.e., the maximum scintillation does not occur at high latitude, but rather slightly to the south of the observer $\left(40^{\circ} \mathrm{N}\right)$. To investigate whether or not figure 14 is contaminated by the aspect-of-propagation effect discussed above and in section 3 it is necessary to examine the azimuth angle dependence. The result is shown in figure 15, in which are plotted those portions of nighttime passages having a zenith angle
40 to $50^{\circ}$. From the magnetic aspect argument the scintillation is expected to be maximum in the magnetic south direction, corresponding to an azimuth of $186^{\circ}$. In figure 15 the two maxima appear only slightly to the south of the observer's latitude in agreement with figure 14 and no maximum appears to the magnetic south. Certainly figures 13 and 14 are contaminated by factors other than the latitude effect, but such contamination must be small, especially during sunspot maximum.

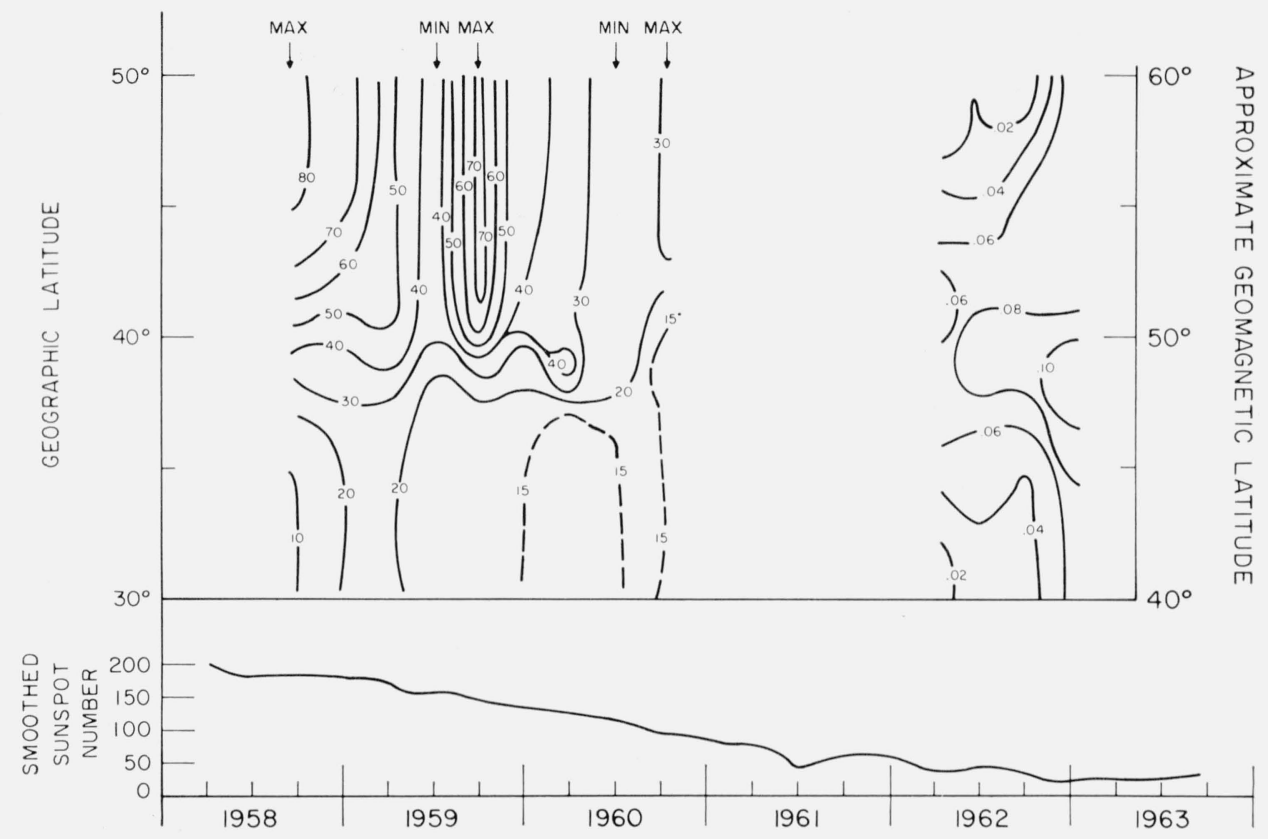

FIgure 16. Contours of equal average scintillation on $20 \mathrm{Mc} / \mathrm{s}$ (percent) and on $54 \mathrm{Mc} / \mathrm{s}$ (scintillation index) near $88^{\circ} \mathrm{W}$.

\subsection{Seasonal and Sunspot Dependence of Nighttime Scintillation}

Studies such as that carried out in 4.2 , for a total of 13 seasons, are combined into a contour plot in figure 16. Also shown in the figure is the smoothed sunspot number. The following observations can be made:

(1) During the sunspot maximum the average scintillation index increases sharply at about $40^{\circ}$ geographic latitude for all seasons.

(2) At high latitudes and during sunspot maximum the average scintillation index is maximum in the fall season and minimum in the summer season, while such seasonal dependence is not apparent at latitudes below $40^{\circ} \mathrm{N}$ or during sunspot minimum.

(3) From 1958 to 1960 , as the sunspot number decreases, there is a general decrease of scintillation superposed on the seasonal dependence. This is especially clear if one compares the maximum scintillation from year to year.
It should be emphasized that the contour plots in figure 16 represent only the average behavior. Actually the scintillation is quite variable from day to day, especially during sunspot maximum. For this reason the average scintillation index and the unbiased estimate of the variance are shown in table 6.

\subsection{The Daytime Scintillation}

The scintillation in the daytime does not show a systematic latitude dependence as does the nighttime scintillation. However, both seasonal and sunspot dependences are quite pronounced as shown in figure 17. From this figure the winter maximum and the summer minimum can be determined, as well as the trend through the years of declining sunspot number. The behavior in 1962 is not yet clear, even though it is not inconsistent with the behavior during sunspot maximum; additional data reduction is necessary to clear up this point. 


\begin{tabular}{|c|c|c|c|c|c|c|c|c|c|c|c|}
\hline \multirow{2}{*}{ Period } & \multicolumn{10}{|c|}{ Latitude } & \multirow{2}{*}{$\begin{array}{l}\text { Num- } \\
\text { ber of } \\
\text { records }\end{array}$} \\
\hline & $30-32^{\circ}$ & $32-34^{\circ}$ & $34-36^{\circ}$ & $36-38^{\circ}$ & $38-40^{\circ}$ & $40-42^{\circ}$ & $42-44^{\circ}$ & $44-46^{\circ}$ & $46-48^{\circ}$ & $48-50^{\circ}$ & \\
\hline $\begin{array}{l}\text { Spring } \\
\text { Summer } \\
\text { Fall } \\
\text { Winter }\end{array}$ & $\begin{array}{r}0.007 \pm 0.001 \\
.035 \pm .014 \\
.025 \pm .006 \\
.064 \pm .005\end{array}$ & $\begin{array}{r}0.024 \pm 0.007 \\
.041 \pm .014 \\
.015 \pm .003 \\
.064 \pm .007\end{array}$ & $\begin{array}{r}0.054 \pm 0.020 \\
.041 \pm .013 \\
.046 \pm .011 \\
.087 \pm .016\end{array}$ & $\begin{array}{r}0.071 \pm 0.025 \\
.071 \pm .017 \\
.065 \pm .021 \\
.103 \pm .025\end{array}$ & $\begin{array}{r}0.067 \pm 0.020 \\
.088 \pm .024 \\
.085 \pm .024 \\
.105 \pm .025\end{array}$ & $\begin{array}{r}0.045 \pm 0.008 \\
.082 \pm .026 \\
.080 \pm .019 \\
.080 \pm .019\end{array}$ & $\begin{array}{r}0.067 \pm 0.020 \\
.061 \pm .018 \\
.063 \pm .027 \\
.075 \pm .014\end{array}$ & $\begin{array}{r}0.045 \pm 0.001 \\
.041 \pm .009 \\
.069 \pm .018 \\
.069 \pm .005\end{array}$ & $\begin{array}{l}0.015 \pm 0.003 \\
.033 \pm .009 \\
.042 \pm .013 \\
.072 \pm .045\end{array}$ & $\begin{array}{r}0.004 \pm 0.001 \\
.024 \pm .008 \\
.012 \pm .003 \\
.067 \pm .004\end{array}$ & $\begin{array}{l}82 \\
66 \\
81 \\
76\end{array}$ \\
\hline
\end{tabular}



Figure 17. Seasonal and yearly dependence of daytime scintillation.

\subsection{Magnetic Activity Dependence}

The maximum scintillation index observed during each nighttime satellite passage has been correlated with the planetary magnetic index, $K_{p}$. The correlation coefficient is 0.15 for the period September 1958 to October 1960 on $20 \mathrm{Mc} / \mathrm{s}$ signals and 0.13 for the period February 1962 to February 1963 on $54 \mathrm{Mc} / \mathrm{s}$ signals. Therefore, the correlation of the scintillation index with the planetary magnetic index is small and positive.

When transition latitude is correlated with $K_{p}$, the resulting coefficient is -0.15 . This indicates the tendency of these transitions to move to a lower latitude when magnetic activity increases. Such an effect has also been noted by Aarons et al. [1963].

\section{Relation to Other Observations}

\subsection{Relation to Irregularities Observed by Other Radio Techniques}

The correlation of the occurrence of irregularities observed by various techniques has been a subject of study by many authors [Briggs, 1958a and 1958b; Calvert et al., 1963; Carpenter and Colin, 1963; Chivers, 1960b; Lawrence et al., 1961; Peterson et al., 1955; Singleton and Lynch, 1962]. An extensive study of the morphology of ionospheric irregularities has been carried out by the study of spread- $F$ [Shimazaki, 1959; Singleton, 1960 and 1962] and by the study of radio star scintillation [Booker, 1958].
The diurnal variations given by figures 9 and 10 generally agree with other observations, especially with regard to the maximum at night. The present result indicates there is some daytime activity which was not observed at Cambridge and which was observed in Australia with a daytime peak almost as large as the nighttime peak. The discrepancy in daytime behavior is often blamed on sporadic- $E$. No sporadic- $E$ statistics are available for comparison with the scintillation data presented herein. (Recently, J. P. McClure of this laboratory has found that most daytime scintillations are caused by irregularities at about $100 \mathrm{~km}$ height.) However, the present data do suggest that, on the average, the daytime scintillation and the nighttime scintillation behave differently in their latitude and seasonal variations.

The experimental observations of radio-star scintillation have not been in agreement with respect to seasonal variation. For example, in Australia [Bolton et al., 1953] winter and summer maxima and spring and fall minima were observed, while in Canada [Hartz, 1955] no apparent seasonal dependence was reported. It is not known whether such observational discrepancies can be reconciled by taking sporadic- $E$, aurora, low angle of observation, latitude effect, variation of $f_{0} F 2$, sunspot cycle and errors in sampling into account. Lawrence et al. [1961], utilizing the cosmic radio source Cygnus $A$, observed minimum scintillation activity in the fall and maximum in the spring. This is inconsistent with the present data and is probably due to the fact that Cygnus A is seen during hours of darkness at their location (Boulder, Colo.) only from March through June. As F-region scintillation occurs almost exclusively at night the Boulder seasonal data may be contaminated by diurnal variations. The seasonal dependence of spread- $F$, as studied by Shimazaki [1959], is such that the probability of occurrence, at latitudes higher than $30^{\circ}$ geomagnetic, is higher in winter than in summer at sunspot maximum. The probability in the fall may at some stations be comparable to that in winter. Thus, the present observations are in general agreement with the spread- $F$ study, especially if allowances are made for differences in observing techniques.

The dependence on latitude given by figures 13 and 16 is in good agreement with spread- $F$ observations [Shimazaki, 1959] in its behavior both in the sunspot maximum and in the sunspot minimum. During. 
sunspot maximum years the scintillation index as well as the probability of occurrence of spread- $F$ increases rapidly as geomagnetic latitude increases from $40^{\circ} \mathrm{N}$ to $60^{\circ} \mathrm{N}$. Due to averaging of data such an increase appears to take place over roughly $5^{\circ}$ in latitude. Satellite observations indicate that in many instances such transitions may be very abrupt, say $10 \mathrm{~km}$ or less. These transition boundaries exist both in the Northern and Southern Hemispheres and at approximately the same auroral isochasms, as indicated by the Nora-Alice experiment. Study of radio star scintillation also indicates a closer connection between the scintillation occurring at higher latitudes in the two hemispheres than between that at high latitudes and at the equator [Brenan, 1960].

The relationship between magnetic activity and irregularities has been studied by a number of authors. Its correlation with spread- $F$ in geomagnetic latitudes 30 to $60^{\circ}$ is in the neighborhood of +0.2 to +0.3 [Shimazaki, 1959]. Peterson et al. [1955], observed negligible correlation between magnetic activity and backscatter from field-alined irregularities. The present investigation yields a correlation of +0.13 to 0.15 (see 4.5). Thus, the correlation of magnetic activity with irregularities is not as striking as with auroral activities, but it is positive.

\section{2. Relation to Subvisual Red Auroral Arcs and the Radiation Belts}

The occurrence of monochromatic $(6300 \AA)$ subvisual auroral ares in mid-latitudes was discovered by Barbier [1958]. Since then extensive observations have been carried out in both Southern [Duncan, 1959] and Northern Hemispheres. These ares occur at times when there is general auroral activity to the north. But there are differences between these two phenomena especially in their geographic positions and their time variations. The heights of maximum luminosity are around $400 \mathrm{~km}$ [Roach et al., 1960; Moore and Odencrantz, 1961]. During a severe geomagnetic storm on November 28, 1959, two Geiger tubes on satellite 1959 ८ (Explorer 7) detected anomalies in the outer radiation zone at a height of about $1000 \mathrm{~km}$. These anomalies appeared to correlate in space and time on a number of satellite passes with the observation of subvisual $6300 \AA$ arcs in the $F$ region. The brightness of these arcs diminished as the radiation zones became less intense [O'Brien et al., 1960]. Based on the observation of an arc on the night of November 27, 1959, King and Roach [1961] explained the emission in terms of an enhancement by three orders of magnitude of the ionospheric recombination coefficient. More recently Roach [1963] found scintillation on the very high frequency radio signals propagated from a polar orbiting satellite through $6300 \AA$ red ares and determined that the scintillation "noise power" (see 2.1) correlates logarithmically with the photon flux determined from the photometric measurements.
In view of the suggested connection between subvisual $6300 \AA$ ares and scintillation phenomenon, table 7 has been prepared to show the satellite radio scintillation observations on nights when red arcs were seen and published in the literature. This table shows that during the appearance of red arcs scintillation was simultaneously observed. Subsequent daytime observations indicated little scintillation if any.

TABLE 7. Transition latitudes of satellite scintillation observed at times of appearance of red arcs $(6300 \AA)$

\begin{tabular}{|c|c|c|c|c|}
\hline Date & CST & $\begin{array}{c}\text { Transition } \\
\text { latitudes }\end{array}$ & Remarks & Literary reference \\
\hline Oct. 22,1958 & 2059 & $41.9^{\circ} \mathrm{N}$ & Sharp transition. & $\begin{array}{l}\text { Roach and Marovich } \\
\quad 1960 .\end{array}$ \\
\hline Nov. 27,1959 & 1250 & - & No scintillation. & \\
\hline Nov. 27,1959 & 1955 & $41.7^{\circ} \mathrm{N}$ & Transition $(30 \mathrm{~s})$. & Roach et al. [1960]. \\
\hline Nov. 28,1959 & 0115 & - & $\begin{array}{l}\text { Strong scintillation } \\
\text { throughout the } \\
\text { passage. }\end{array}$ & O'Brien et al. [1960]. \\
\hline April 2,1960 & 0023 & - & $\begin{array}{l}\text { Strong scintillation } \\
\text { throughout the } \\
\text { passage. }\end{array}$ & $\begin{array}{l}\text { Moore and Oden- } \\
\text { crantz [1960]. }\end{array}$ \\
\hline April 2,1960 & 0551 & 一 & $\begin{array}{l}\text { Scintillation through- } \\
\text { out the passage. }\end{array}$ & \\
\hline April 2,1960 & 0928 & - & $\begin{array}{l}\text { Only one small patch } \\
\text { of scintillation. }\end{array}$ & \\
\hline Oct. $\quad 1,1961$ & 0052 & $37.9^{\circ}$ & Fairly sharp transition. & $\begin{array}{l}\text { Tohmatsu and } \\
\text { Roach [1962]. }\end{array}$ \\
\hline
\end{tabular}

In the following a more detailed discussion of each of these events is given.

(A) October 22, 1959, Event: Auroral activities observed to the north. At 2100 CS'T the boundary of the $6300 \AA$ arc was at about $53^{\circ} \mathrm{N}$ geomagnetic and the scintillation boundary was found to be at about $52^{\circ} \mathrm{N}$ geomagnetic (or $42^{\circ} \mathrm{N}$ geographic). Since the determination of the boundary requires the assumption of height in both observations such correspondence is considered to be good.

(B) November 27 and 28, 1959, Event: Sudden commencement at 1750 CS'T November 27. Auroras observed. Close correlation of the aurora and the red arc with the outer radiation belt detected [O'Brien et al., 1960]. The 1955 CS'T pass had a transition roughly at $42^{\circ} \mathrm{N}$, and the 0115 CST pass had scintillation throughout the passage. The first photometric observation was made at 2222 CST when the arc was moving steadily south. At 0115 CST, the band of the red arc appeared within the dip angle range 66 to $72^{\circ}$, while the radiation counting rate had a maximum near this range and decreased but was still appreciable to the north of the band and decreased to a negligibly small amount to the south of the band. The height of the red arc was found to be at $400 \mathrm{~km}$ by triangulation [Roach et al., 1960]. These observations are quite compatible with the scintillation results.

(C) April 1 and 2, 1960, Event: Magnetic storm occurred. During the period 0015 to 0515 CS'T the height of the red arc was determined to be slightly above $400 \mathrm{~km}$, and its geographic position was fairly constant in the dip angle range 65 to $67^{\circ}$. Very strong scintillation was observed at 0023 
CS'T almost throughout the passage except to the far south where the scintillation was slightly weaker. The scintillation at 0551 CS'T was weaker than at 0023 CST and the scintillation was very weak south of $35.9^{\circ} \mathrm{N}$. Again, the scintillation observation suggests its correlation with the red arc. The observation next day at 0928 CST indicated only one small patch of irregularities.

(D) September 30 and October 1, 1961, Event: Red arcs observed [Tohmatsu and Roach, 1962] at Fritz Peak $\left(39.9^{\circ} \mathrm{N}, 105.5^{\circ} \mathrm{W}, 49^{\circ}\right.$ geomagnetic). At 2130 the arc extended $20^{\circ}$ south to $40^{\circ}$ north in zenith angle and at 2144 it extended $5^{\circ}$ south to $45^{\circ}$ north in zenith angle at Fritz Peak. The scintillation observation $1 \frac{1}{2} \mathrm{hr}$ later indicated the southern boundary at $38^{\circ} \mathrm{N}$ or $48^{\circ}$ geomagnetic which compares favorably with the red arc observation.

The observation of these four events, the agreement in heights of red arcs and the irregularities, and also the work of Roach [1963] suggest strongly that when the ionosphere is perturbed sufficiently during the presence of red arcs the radio signals passing through it will scintillate. However, the converse is not necessarily true since red arcs are fairly rare while scintillation is quite common, and red arcs are correlated with magnetic activity while the scintillation has very weak correlation with magnetic activity. It seems plausible, therefore, that the ionosphere is constantly perturbed by some agency so that scintillation is a common phenomenon at night, especially near sunspot maximum, and if such perturbation is intense enough it may also excite red arcs.

The study of the trapped radiation from the satellite Explorer 6 first showed the existence of the bifurcation of the outer belt [Fan et al. 1960]. Stolov [1962] postulated that the $E_{2}$ belt might be responsible for the red arc phenomena and the $E_{3}$ for the aurora. Additional observations showed that the radiation is strongly varying and may at times have double or multiple peaks [Van Allen, 1962]. Positions of the maximum intensity of the outer zone plotted by Lin and Van Allen [Van Allen, 1962] agree with the latitude dependence of the scintillation if we postulate that the maximum radiation near the horn of the outer zone, just above the bottom of exosphere, is related to the occurrence of irregularities. Several workers have postulated the creation of irregularities as a result of corpuscular dumping [Peterson et al., 1955; Shimazaki, 1959, and others]. O'Brien and Laughlin [1963] suggest that the dumped electrons may not be sufficiently energetic to excite the $6300 \AA$ line of the red arc.

\section{Conclusion}

It has been found experimentally over a period of 5 years that the irregularities that cause scintillation occur mainly in a narrow height range from about $300 \mathrm{~km}$ to $400 \mathrm{~km}$. The statistical size of these irregularities is of the order of one kilometer per- pendicular to the magnetic field and may be latitude-dependent. Nighttime scintillation is much more common than daytime scintillation and the two differ in character. The nighttime scintillation shows a strong latitude dependence, being more pronounced north of $50^{\circ}$ geomagnetic. At higher latitudes and near sunspot maximum the seasonal and sunspot cycle dependences are very clear, while no such regularity has been found at lower latitudes or near sunspot minimum. There is some evidence from the Nora-Alice experiment that transitions from scintillation to no scintillation occur in northern and southern hemispheres at geomagnetically conjugate points. During magnetic disturbances these transitions tend to occur at lower latitudes. The existence of scintillation has a small positive correlation with magnetic activity. The daytime scintillation shows little latitude dependence. Seasonally the maximum appears in winter near sunspot maximum and the sunspot cycle dependence is also fairly strong.

It has been shown here, as well as elsewhere [Roach, 1963], that scintillation is observed simultaneously with red arcs. By taking into account elastic as well as inelastic collisions, Megill and Carleton [1964] have found that an electric field

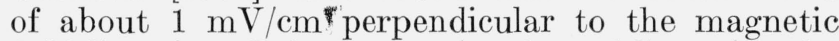
field lines is sufficient to excite the red line with the observed intensity but not the green line. The hypothetical electric field is assumed to have its origin in the interaction of the magnetosphere with the solar wind. Since the assumed electric field is perpendicular to the magnetic field, it induces an $\mathrm{E} \times \mathrm{B}$ drift in the east-west direction of about 2 $\mathrm{km} / \mathrm{s}$ and on rare occasions such a high velocity has reportedly been observed during magnetic disturbances [Briggs and Spencer, 1954]. It should also be noted that such a high drift velocity is comparable with satellite velocity (about $7 \mathrm{~km} / \mathrm{s}$ ) and it is certainly within the capability of satellite scintillation observations to discern its existence. It is not known if red ares and irregularities have a common causative mechanism. If such is the case, scintillation would appear to be the more sensitive indicator of ionospheric perturbation by virtue of its greater frequency of occurrence.

\section{References}

Aarons, J., J. Mullen, and S. Basu (1963), Geomagnetic control of satellite scintillations, J. Geophys. Res. 68, 3159-3168.

Barbier, D. (1958), L'activite aurorale aux basses latitudes, Ann. Geophys. 14, 334-35.5.

Basler, R. P., and R. N. DeWitt (1962), The heights of ionospheric irregularities in the auroral zone, J. Geophys. Res. 6\%, $587-593$.

Bolton, J. G., O. B. Slee, and G. J. Stanley (1953), Galactic radiation at radio frequencies. VI. Low altitude scintillation of the discrete sources, Australian J. Phys. A6, 434-451.

Booker, H. G. (1958), The use of radio stars to study irregular refraction of radio waves in ionosphere, Proc. IRE 46, 298-314.

Booker, H. G., and H. W. Wells (1938), Scattering of radio waves by the $F$-region of the ionosphere, J. Geophys. Res. 43, $249-256$. 
Bowles, K. L., B. B. Balsley, and R. Cohen (1963), Fieldaligned E-region irregularities identified with acoustic plasma waves, J. Geophys. Res. 68, 2485-2501.

Brenan, P. M. (1960), The correlation of radio source scintillation in the Southern and Northern Hemispheres, J. Atmospheric Terrest. Phys. 19, 287-289.

Briggs, B. H. (1958a), A study of the ionospheric irregularities which cause spread- $F$ echoes and scintillations of radio stars. J. Atmospheric Terrest. Phys. 12, 34-45.

Briggs, B. H. (1958b), The diurnal and seasonal variations of spread- $F$ ionospheric echoes and the scintillations of a radio star, J. Atmospheric Terrest. Phys. 12, 89-99.

Briggs, B. H., and J. A. Parkin (1963), On the variation of radio star and satellite scintillations with zenith angle, $J$. Atmospheric Terrest. Phys. 25, 339-365.

Briggs, B. H., and M. Spencer (1954), Horizontal movements in the ionosphere, Reports on Progress in Physics 1\%, $245-280$.

Calvert, W., T. E. VanZandt, R. W. Knecht, and G. B. Goe (1963), Evidence for field-aligned ionization irregularities between 400 and $1000 \mathrm{~km}$ above the earth's surface, Proc. of the International Conference on the Ionosphere in London, July 1962 (Institute of Physics, Physical Society, $324-329$ ).

Carpenter, G. B., and J. Colin (1963), On a remarkable correlation between whistler-mode propagation and highfrequency northscatter, J. Geophys. Res. 2, 5649-5658.

Chivers, H. J. A. (1960a), The simultaneous observation of radio star scintillations on different radio-frequencies, $\mathrm{J}$. Atmospheric Terrest. Phys. 17, 181-187.

Chivers, H. J. A. (1960b), Observed variations in the amplitude scintillations of the Cassiopeia (23NrA) radio source, J. Atmospheric Terrest. Phys. 19, 54-64.

Chivers, H. J. A. (1963a), The location of the irregularities responsible for ionospheric scintillation of a radio source, Proc. of the International Conference on the Ionosphere in London, July 1962 (Institute of Physics, Physical Society, 258-266).

Chivers, H. J. A. (1963b), Radio star scintillations and spread-F echoes, J. Atmospheric Terrest. Phys. 25, 468-472.

DeBarber, J. P., G. E. Chisholm, and W. J. Ross (1963), The nature of the irregularities in ionization density causing scintillations in satellite signals, Proc. of the International Conference on the Ionosphere in London July 1962 (Institute of Physics, Physical Society, 267-270).

DeMendonca, F. (1960) (private communication).

Duncan, R. A. (1959), Photometric observations of subvisual red auroral ares at middie latitudes, Australian J. Phys. 12, $197-198$.

Fan, C. Y., P. Meyer, and J. A. Simpson (1960), Trapped and cosmic radiation measurements from Explorer VI, Proc. First International Space Science Symposium, ed. H. K. Kallman-Bijl, 951-966 (North Holland Publishing Co., Amsterdam).

Farley, D. T., Jr., (1963), Two-stream plasma instability as a source of irregularities in the ionosphere, Phys. Rev. Letters 10, 279-282.

Frihagen, J., and J. Troim (1960), Scintillation of the $20 \mathrm{Mc} / \mathrm{s}$ signal from the earth satellite $1958 \delta$ II, J. Atmospheric Terrest. Phys. 18, $75-78$.

Frihagen, J., and J. Tr $\phi$ im (1961), On the large scale regions of irregularities producing scintillation of signals transmitted from earth satellite, J. Atmospheric Terrest. Phys. 20, $125-216$

Hartz, T. R. (1955), Radio star scintillations and the ionosphere, Can. J. Phys. 33, 476-482.

Helliwell, R. A., J. H. Crary, J. H. Pope, and R. L. Smith (1956), The nose whistler, a new high latitude phenomenon, J. Geophys. Res. 61, 139-142.

Hewish, A. (1952), The Diffraction of galactic radio waves as a method of investigating the irregular structure of the ionosphere. Proc. Roy. Soc. A214, 492.

Hey, J. S., S. J. Parsons, and J. W. Phillips (1946), Fluctuations in cosmic radiation at radiofrequencies, Nature (London) 158, 247.

Kent, G. S. (1959), High-frequency fading ubserved on the $40 \mathrm{Mc} / \mathrm{s}$ wave radiated from artificial satellite $1957 \mathrm{a}$, J. Atmospheric Terrest. Phys. 16, 10-20.
King, G. A. M., and F. E. Roach (1961), Relationship between red auroral ares and ionospheric recombination, J. Res. NBS 65D (Radio Prop.), No. 2, 129-135.

espersen, J. L., and G. Kamas (1964), Satellite scintillation observed at Boulder, Colo., J. Atmospheric and Terrest. Phys. 26, 457-473.

Lawrence, R. S., J. L. Jespersen, and R. C. Lamb (1961), Amplitude and angular scintillations of the radio source cygnus-A, J. Res. NBS 65D (Radio Prop.), No. 4, 333-350.

Liszka, L. (1963a), Satellite scintillation observed in the auroral zone, Arkiv. Geofysik 4, 211-225.

Liszka, L. (1963b), A study of ionospheric irregularities using satellite transmissions at $54 \mathrm{Mc} / \mathrm{s}$, Arkiv. Geofysik 4, $227-246$.

Little, C. G., G. C. Reid, E. Stiltner, and R. P. Merritt (1962) An experimental investigation of the scintillation of radio stars observed at frequencies of 223 and 456 megacycles per second from a location close to the auroral zone, J. Geophys. Res. 6\%, 1763-1784.

Maeda, K. T. Tsuda, and H. Maeda (1963), Theoretical interpretation of the equatorial sporadic $E$ layers, Phys. Rev. Letters 11, 406-407.

Mawdsley, J. (1960), Fading of satellite transmissions and ionospheric irregularities, J. Atmospheric Terrest. Phys. 18, 344.

Megill, L. R., and N. P. Carleton (1964), Excitation by local electric fields in the aurora and airglow, J. Geophys. Res. 69, $101-122$.

Moore, J. G., and F. K. Odencrantz (1961), The height and geographical position of the red auroral arc of April 1-2, 1960, J. Geophys. Res. 66, 2101-2104.

Munro, G. H. (1963), Scintillation of radio signals from satellites, J. Geophys. Res. 68, 1851-1860.

O'Brien, B. J., J. A. Van Allen, F. E. Roach, and C. W. Gartlein (1960), Correlation of an auroral are and a subvisible monochromatic $6300 \mathrm{~A}$ are with outer-zone radiation on November 28, 1959, J. Geophys. Res. 65, 2759-2766.

Parthasarathy, R., R. P. Basler, and R. N. DeWitt (1959), A new method for studying the auroral ionosphere using earth satellites, Proc. IRE 4\%, 1660.

Peterson, A. M., O. G. Villard, R. L. Leadabrand, and P. B. Gallagher (1955), Regularly-observable aspect-sensitive radio reflections from ionization aligned with the earth's magnetic field and located within the ionospheric layers at middle latitudes, J. Geophys. Res. 60, 497.

Rawer, K. (1962), Propagation problems with space radio communications, J. Res. NBS 66D (Radio Prop.), No. 4, $375-393$.

Rice, S. O. (1944), Mathematical analysis of random noise, Bell System Tech. J. 23, 282-332.

Rice, S. O. (1945), Mathematical analysis of random noise, Bell System Tech. J. 24. 46-156.

Roach, F. E., and E. Marovich (1960, Aurora of October 23, 1958, at Rapid City Dakota, J. Res. NBS 64D, (Radio Prop.), No. 2, 205-209.

Roach, F. E., J. G. Moore, E. C. Bruner, Jr., H. Cronin, and S. M. Silverman, The height of maximum luminosity in an auroral are, J. Geophys. Res. 65, 3575-3580.

Roach, J. R. (1963), Effects of radio wave propagation through mid-latitude $6300 \mathrm{~A}$ auroral ares, J. Res. NBS 6rD (Radio Prop.), No. 3, 263-271.

Shimazaki, T. (1959), A statistical study of world-wide occurrence probability of spread- $F$, Part 1 , A verage state, Part 2, Abnormal state in severe magnetic storms, J. Radio Research Laboratories (Japan) 6, 669-704.

Singleton, D.G. (1960), The geomorphology of spread-F, J. Geophys. Res. 65, 3615-3624.

Singleton, D.G. (1962), Spread- $F$ and the parameters of the $F$-layer of the ionosphere, J. Atmospheric Terrest. Phys 24, 871-920.

Singleton, D.G., and G. J. . Lynch (1962), The scintillation of the radio transmissions from Explorer 7, J. Atmospheris Terrest. Phys. 24, 353-374.

Slee, O. B (1958), Radio scintillations of satellite 1958 a Nature (London) 181, 1610.

Spencer, M. (1955), The shape of irregularities in the upper atmosphere, Proc. Phys. Soc. 68B, 493-503.

Stolov, H. L. (1962), Bifurcation of the outer Van Allen belt and related auroral phenomena, J. Geophys. Res. 67, 404-406. 
Swenson, G. W., Jr. (1962), The utilization of ionosphere beacon satellites, NASA Technical Note D-1669, 91-117. Tohmatsu, T., and F. E. Roach (1962), The morphology of mid-latitude 6300 angstrom ares, J. Geophys. Res. 67, $1817-1822$

Van Allen, J. A. (1962), Dynamics, composition and origin of the geomagnetically-trapped corpuscular radiation, Transactions of the international astronomical Union XIB, $99-136$.

Vestine, E. H., and W. L. Sibley (1960), Geomagnetic field lines in space, Rand Report R-368 (The Rand Corp.).

Wild, J. P., and J. A. Roberts (1956), The spectrum of radiostar scintillations and the nature of irregularities in the ionosphere, J. Atmospheric Terrest. Phys. 8, 55-75.
Yeh, K. C. (1962), Propagation of spherical waves through an ionosphere containing anisotropic irregularities, J. Res. NBS 66D (Radio Prop.), No. 5, 621-636.

Yeh, K. C., and G. W. Swenson, Jr., (1959), The scintillation of radio signals from satellites, J. Geophys. Res. 64, 22812286.

Yeh, K. C., G. W. Swenson, Jr., and J. P. MeClure (1963), A phenomenological study of scintillation on satellite radio signals, Spring URSI Meeting, Washington, D.C.

(Paper 68D8-386) 